\title{
Jørgen B. Høyer. \\ Vandreren i Mellemslesvig.
}

\author{
Af August F. Schmidt.
}

I 1885 og $18 x \tau$ foretog H. P. H a n s s e n Fodı ejser i Mellem. slesvig for at blive bekendt med de nationale og sproglige loohold i cle Egne, hvor Dansk og Tysk da modtes. I en lixngere Artikel i Højskolebladet 1887') giver han en læererig og fangslende skildring af sine Rejser's Resultater, $\left.{ }^{2}\right)$ der senere fik en god Støtte i H. V. C.lausens s progkort fra 1889.") Dette Kort er udarbejdet pă Grundlag af 1) Meddelelser fra pålidelige Mænd i Mellemslesvig, hvor sprogene moles, 2) efter Samlinger fra P. La u ridsen og 3) efter Iagttagelser, som Clausen selv havde gjort pă Rejser i souderjylland gennem snart mange År. Bag pă Kortet stod trykte Oplysninger. Senere uddỵbede Clausen sine Studier i Mellemslesvigs (og hele Sønderjyllands) sprogforhold $i$ en langere Afhandling i Sønderjydske Aarbøger 1892-93, 183 213, 85-105, udformet som en Kritik af $J$. G. C. A d lers Arbejde: Die Volkssprache in dem Herzogthum Schleswig seit 1864. I Sønderjyctske Aarboger 1894, 33-14; fortsæetter Clausen sine dỵbtgående Studier i Sprogforholdene i vort Grænseland og giver hermed al den Besked, man kunde ønske om Fordelingen af Dansk og Tysk overalt i Sønderjylland. Det siger sig selv, at senere Forskere i Nationalitetskampen ved det danske lolks sydgranse har haft det bedst mulige U'dgangspunkt i Clausens Arbejder, der naturligvis må have haft stor Betydning for cand. theol. Jorge $\mathrm{J}$ B oye H o y e r, der i sin Cerning som Udsporger og Indsamler på sine

1) Optrykt i H. P. Hanssen: Fra Kampaarene I (19:7), 7-29.

2) Rejserne i Mellemslesvig har Hanssen kort omtalt i Et Tilbageblik $(1928), 131-33,163-64$.

a) Jfr. hermed Marius Kristensens Sprogkort i Sonderjyllands Iristorie I, 81 . 
Rejser i Mellemslesvig i Arene 1902-1909 udrettede et Arbejde, son fortrinligt uddybede og befæstede, hvad $\mathrm{H}$. V. Clausen $\mathrm{i}$ 189294 havde of entliggjort om Sønderjylland under Fremmedherredømmet. ${ }^{1}$ )

J ørg e n B oy e Høyer blev folt den 27. Juni 1875 i A rhus, hror hals Fader dengang var Skolebestyrer. Forældrene var begge Sonderjyder. Faderen $\mathrm{N}$ is s J o ch u mse $\mathrm{n} \mathrm{Høyer}$ var fra H o vsl u nd, hvor han blev født 5. November 1840. Hans Fader var Gårdejer Jørgen Mortensen Høyer og Moderen Karen Høyer, født Toft, fra D i e r $\mathbf{n}$ æs ved Slivminde. J. M. Høyers Fader var Gårdejer Oluf Pedersen Høyer, gift med Mette Lauritsdatter. Hans Fader igen var Peder Nielsen Høyer, Gårdejer i Ustrup, født i September 1736. Han var Søn af en Boelsmand fra Vedsted Sogn, hvori Ustrup ligger. Boelsmanden havile arbejlet sig frem, så han blev Ejer af en Helgård.

Pastor N. J. Høyer blev Student fra Haderslev 1863 og cand. theol. 1873. Samme Ar blev han Skolebestyrer i Århus. Han blev gift i sejlflod den 29. December 1873 med sin Kusine Anna Magdalene Hoyer, født 21. November 1847 i Øster Lindet, Datter af Gårdejer, Sognefoged B o y L a uritze $n$ H y yer (der var Broder til Jørgen Mortensen Hoyer) og Hustru A n ne Hansdatter. ${ }^{2}$ ) I N. J. Høyers og Anna Magdalene Høyers Egteskab fødtes som nævint Sømmen Jørgen Boye Haỵer. Kun få År havde han sit Barndomshjem i Jyllands Hovedstad, idet Faderen 10. Marts 1881 blev kaldet til Sogneprast for K voug-L y ne Menigheder Nord for Varde. Herfra søgte han og fik den 23. Juli 1891 Embedet som Sognepræst for Vils lev og $\mathrm{Hunderup}$ ved Kongeåen Nord for Ribe. Her forblev han, til han tog sin Afsked den 4. September 1911. Han døde 4. December 1919 i Ribe.") Pastor Høyer karak-

1) Jfr. H. V. Clausen: Før Afgørelsen (1918), om Mellemslesvigs Hesleegne, $20 \mathrm{ff}$.

*) I)e fleste ovenstăende Slægtsoplysninger har jeg ned Tak morltaget fra Forpagter J ens $\mathrm{H}$ ø y e r, Billeslund.

3) Th. Hauch-Fausholl og Max Grohshennig: Danmarks Præstehistorie II 1932 , S. 405. 
tepiseres som en velmenende Mand, men ikke som nogen særlig fremragende Begavelse. Som ung skal han have været en lystig Fyr.

Hans Hustru, der var Søster til Gårdejer Oluf $\mathrm{H}$ øy er (iøod 1922) i Øster Lindet og Faster til Jens Høyer på Billeslund, var der nok Krummer i, men hun var noget bjergtagen af, at hun var "Præstefruen«. Hun var en af de yngste i Søskenleflokken. De æeldste af hendes Søskende var vokset op i en fattig Tid, og der blev tidlig stillet store Krav til dem, hvad Aer pragede dem Livet igemnem. De blev gode Xkonomer og var dygtige og stødte aldrig an mod "god Tone". Derimod var l.ru Amma Høyer urolig og vist ikke særlig dygtig som Husmoler, men det var alligevel hende, der prægede Prastehjemmet. Hun døde den 22. December 1922 i Christiansfeld, hvor en Datter (r) gift nied Restauratør M. Por's, »Frej«.

I Jørgen B. Høyers Slægt er der mange kendte Navne, især fl'a Øster Lindetegnen, săsom Oluf Høyer, Kristian Høyer, Hans Høyer, Boy Høyer, Jens Høyer og Axel Høyer, alle kendte for deres udpræagede danske sind.

Jorgen IIøyer blev student fra Ribe $1895 \mathrm{og}$ tog theologisk Embedseksamen i Sommeren 1901.') Han følte efter enılt Eksamensstudium ikke Trang til straks at blive Præst. Han fandt, at Skolevirksomhed lå bedre for ham, isar stod hans $\mathrm{Hu}$ til at blive Lærer for voksen Ungdom. Han besøgte ofte den tidligere Forstander for Brøderup og Janderup Hojskoler Jesper M a d s n, (ler henlevede sine sidste Dage som fhv. Bankdirektor i Jerne ved Esbjerg. For ham udviklede Høyer sine Tanker on Hojskolegerningen. Han fik også Plads som L:rer pă et Par mindre Højskoler, sidst på Kærehave Husmandsskole ved Ringsted, indtil han i Efteråret 1909 efter Opfordring overtog Stillingen som Forstander for den nyoprettede Højskole i skelu nd ved Hadsund i Sydøsthimmerland. Her i denne ejendlommelige skøme Egn var allerede i 1870 blevet

\footnotetext{
1, O. Lamkier: Gejstlig stat 1903 [1903], s. 19.
} 
oprettet en Hojskole af J. F. H a $m$ mer. I nogle Ar var Skelund Hojskole tenmmelig godt besogt. Men da Elevtallet hen i Firserne dalede betydeligt, solgte Hanmer skolell og begyndte en ny Virksomhed i Srup pa Fyn. $18 \times 6$ blev skelund Folkehojskole nedlagt. ${ }^{1}$ ) Men i 1909 begyndte den altsa sin Virksomberl pany med Hoyer som Forstander. Skolen indviedos Fredag dell 4. November 1909.2) Ina Jorgen B. Hoyer begyndte sin Gerning som Hojskoleforstander, var hans V'irksomhed som skribent i Mellemslesvig sluttet. Det vil derfor vare passende her at fortælle om Hoyers historiske Indsats.

Som de fleste Lokalhistorikere saledes begynulte ogsan Hoyer med sturlier $i$ sit Hjemsogns Historie. Det var navnlig don historisk interesseredle Prast Knud Lang (i Vilslev 17't1781), der tiltrak sig hans Opmarksomhed. Af deme P'rasts Optegnelser udgav Hoyer i Fra Ribe Amt I (1903), 138-140 ent Skihring af hvargpestell i Vilsleveguen 1769 71 samt hans verdifulde og urlforlige Medclelelser fra 17 tix on Vilsle Sogu") (i samlinger til jyclsk Historie og Topografi 3. Rakke, 1V. Bind 1904 05, 38 9(i). Hoỵer năelle ikke senere at yde Bidrag til det navute Kongeasogus Histerie. Den Tid, han fik tilovers i de kommemle hr, blev brugt til somderjydske Rejser og studier. Med Evner til videnskabeligt studium la det ner for ham at ga til Bumls i ell sag. Derfor fallt det ham naturligt selv at rejse ned og undersoge Forholdene i Mellemog sirdslesvig. Sporgsmalet for han var dette: Hvor lange kan sonderjydene liolde ud i hampen mod det tyske sprogs og let tiske Simlelags Fremtrongen? Vil den Dag ikke ligge narr, da Mellemslesvig ligesom allerede Sydslesvig og Angel er tabt? Det var ham Sanvittighedssporgsmal, han máte have besvarede. Og sa drog han dermed, gemmemvandrede $i$ sine Ferier Mellentslesvig pá Kryds og Trers, fra Tonder i

1) Nombahl-Potersen: I)anmanks Ihojskoler 11900), S. 239.

$\Rightarrow$ Ilojsliolebladet 19\%9, sp. 15isk.

") Om Vilstev Sogn har Jesper Madtsen skrevot en Jfhandling i Fra Rilu. dunt III (19(0)5), :? 
Nord til svesing i Sird, fra B ov i Wst til Silds Havklitter i Vest.

Heldigvis har Jorgen Hoyer i nogle pragtige Skildringer fortalt om sine studierejser i let onstridte Land. Hans Ari) ojder herom er offentliggjorte i Hojskolebladet og i sonderjydske Aarboger 19031909 i folgende ret onfangsrige Afhandlinger og Artikler:

1) En Fodturgenue suroggrasen (Hojskole-

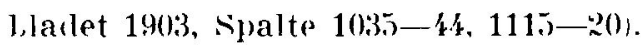

2) E川 liejse gennell Overgangseguene fra ll a nsk til tysk (Simderjydske Larboger 1905, 1-42).

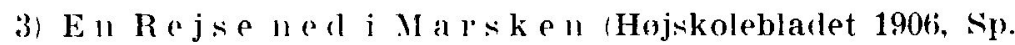
$\div 1 \quad(30,83960)$.

4) Desproglige og nationale lijstande paa Mellemslesvigs Hajdryg ved det 20 . A arhun-

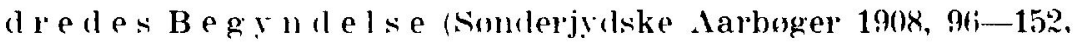
165 $19 \%$.

5) B l a ll dt Nordfriser lla (Hojskoleblatet 1909, Sp. $73358,7 \times 9 \quad 94)$.

Jorgen B. Hoyers forste Rojse sydpa fandt sted i slutningen af $11 \mathrm{gu}$ : t $190 \%$. I skildringen af den (Bibliografien Nr. 1) er der, som overalt hos ham,, smukke Naturbilleder og gode Memmeskeskildringer. Han kunde glarde sig meget over landskabelig Skmuhed, hans Iagttagelsesevuer var gode, og han formaede uden spor af kumstmeriske Virkemiller at skildre Egne og Menmesker sa umirlelbart fangslende og rigtige, at man underligt lover med i det hele dernede i Landet siyd for Tondor, nar man folger lam i hais Rejseoplevelser. Han kom i

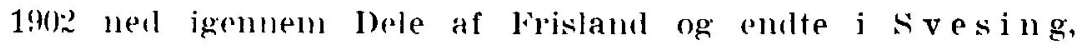
stell uforbederlige tyske By", hvor han besogte Prest og Degn.") Fra svesing spadsepede han nordpa til F jol le, hvor han traf en rolde Mand, der kunde Dansk. En tysk Bolge var slaaet ind over Byels, hvor den ảnılelige Jordbund var

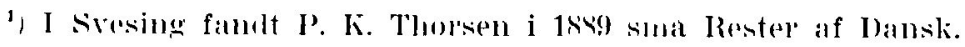


vel forberedt til at modtage det fra syd kommende Sprog. Dansk var her indeklemt af Tysk fra (Wst og syd og af Frisisk fra Vest. Fra Fjolde gik Turen til Lovsted og $\mathrm{H}$ joldeI und; dernæst til Goldebæk. I de tre Byer taltes ikke Dansk til daglig, medens Høyer i Nørre-Haks te $\mathbf{N}$ Kro traf on Mand, der talte vort Sprog flydende.

Den næste Rejse fandt Sted i Juli 1903 (se Bibliografien Nr. 2). IIdgangspunktet var B y l d e r u p-B ov. Herfra gik 'Juren til Rens og La d e l u n d. I sidstnievnte By var Høyer ude på Kirkegården. Pă et Kors stod: "Vi skulle ved megen Bedrovelse indgaa i Guds Rige« (S. 18). Fra Ladelund drogVandringsmanden astpa til Medelby, Valsbolog sitore $V^{\top}$ i. Man laser med sierlig Interesse, hvad Hoyer fik at vide hos ældre Folk om H. F. Fe il berg, der var Prast i lle to sidstnævnte Sogne i Arene 1859-6:, 1862-64. Hans Bog »Fra Heden « syntes de ikke ret om. Det var noget underligt noget at skrive om gamle Sæder og Skikke (S. 30-32).') Folk har her som sả mange andre Steder ikke haft Forudsætninger for at forstå Betyduingen af Verker on en Egus Alunueliv. Fra St. Vi tog Hoyer til sill erup, den sydvestligste By i let udstrakte St. Yi Sogn. Her havile det danske Sprog holdt sig bellre end $\mathrm{i}$ Sognets ovrige Brer. Grunden hertil var sikkert den afsides Beliggenhed; Befolkningen udgjorde nasten et Familieskab, sà det var lerfor sarlig svart sadan et sted at bryde med gammel Sred og Vane. Turen sluttedes i J or l Sogn syd for sillerup. Man befandt sig her på Fortyskningens 4. og sidste Triu (s. 40 ). Derimod havde I)ansk med en markelig sejghed holdt sig i B o n d e l u m sydostligst i det store Fjolcle sogn. Her havde det danske Sprog dannet en Slags Enklave Syd for den egentlige Sproggrænse. ${ }^{2}$ ) Byens isolerede Beliggenhed bovirkede, at Folk

1) Jfr. Dansk Ingdom 15. 4. 1921. Holger Hjelholt: Smnderjydsk sprog- og Folkemindeforskning mellem Krigene. (I)anske Studiel 1919,129 ff.).

2) Se Kortet i H. V. Clausens Afhandling. (Sij. Aarb. 1892, 184). Dette Kort hør man have ved Hânden, når man laser Høyers Skildringer, både for Ruternes og Tallenes Skyld. Man má heller ikke undlade at læse H. P. Ha nssens Rejseskildringer frit le mellem- 
var yderst konservative, sa Dansk kunde holde sig lingere hel end i Nabobyerne.

I Forbindelse med denne Rejse mä Høyer have foretaget eır Tur til Marske n (Bibliografien Nr. 3). Den fandt nemlig ogsa Sted i J u li 1903 . Af stor Udstrækning var Marskbesøget ikke. Rejsen gik over Ballum, Højer, Hadenæs til K langsbol. Derfra tog han nordpå til Hestbol, 'Tonder og Møgeltønder. Det blev altså kun den nordlige Marsk, han fik besøgt. Skildringen af Rejsen er sardeles underholdende, og man fár en hel Del at vide om de nationale Forhold i let berejste lille Område. I Rødenæs var Folk tyske. Aar 190n var der 97 Familier, i 53 var Hussproget Frisisk, i 27 Dansk, i i Højtysk, i 6 Plattysk og i 4 blandet. I Klangsbøl, hvor Høyer besogte Stedets lærde Præs $t^{1}$ ), var der 12 dansksindede. Resultatet af Rejsen for Hoyer var, at det frisiske Sprog altid er vigende i Beroringen med Plattysk eller Dansk. Derfor har vort Sprog gjort sig forholdsvis stærkt gældende efter 1864 i den nordlige Del af den ellers tysksindede Marsk. Først når Plattysk bliver herskende, vil ogsaa Dansken her vige.

Sin starste slesvigske Rejse foretog $\mathrm{H}$ g yer i som me re 1907 (Bibliografien Nr. 4). Den gik til Mellemslesvig : $\mathrm{H} ø \mathbf{j} \mathrm{d}$ e r y g, hvor han vilde modtage et Indtryk af de sproglige og nationale Tilstande, som de var o. 190\%. Rejsen blev udbytterig og affølte Høyers storste skriftlige Arbejde, som man i de følgende Bemærkninger om Rejseruten mảske kan fă et lill» Indtryk af.

Jørgen Høyer begyndte sin Rejse i $\mathrm{H}$ a $n$ ve d og tog derfra over Frøslev, Ellund og Medelby til Østerby. Foruden at tale med Folk om sproglige og andre nationale Forhold. benyttede han også Lejligheden til at høre lidt om xldre historiske Tildragelser, Folkeminder o. s. fr. I Osterby optegner han

slesvigske Herleegne i Sammenhang med Clausens og Inyer's Arbejder. I Bogen: Fra Kampaarene I (1927), 14-15 er der oplysninger leolsaget af et Kort - , der fortrinligt supplerer Hoyers Bemalkninge! om Sprogforholdene i Hjoldelund, Fjolde og Lick.

1) Ernst Michelsen. 
et Minde fra Kosaktiden (S. 111), i Medelby horer han noget om Krigen 1848 (slaget ved Bov), ligesom ogsa Krigen dér og andre Steder pả Rejsen hyppigt var Samtaleemue. Javulig blev A. C. Ri is-L ow son omtalt af Folk, navnlig i en stor Omegn af L $2 \mathrm{k}$, hvor Riis-Lowson var Præst i Tiden 1858 18ti4, da han blev forjaget. I de tysksindedes Kredse var der ingen, der fortalte noget godt om denne Mand, der angives at have været meget stivmakket og tilbojelig til at kme Folk i stramme Tøjler. I en national blandet Egn vil en Embedsmand af den Slags let få mange Modstandere. Hans Minde levede golt nok i Lækeguen i 1907 (se S. 114, 141, 172, 177), ligesom hans skolekammerat $H$. IF. Fe ilbergs i Valsboleguen, men cler var dog nogen Forskel pa Omtalen af de to hver pa tleres V'is hetridelige Mand, da Hoyer spurgte ud on dem pà sine Rejser.')

I Medelbyegnen hjemsingte Hoyer agna Byerne Holte, Ves by, B ogs l u n d og J a r l u n d. Derfra drog lan til V a I sbøl, Mejn, Nr. Haksted, Skovlund og Horup. Fra disse Byel, hvor Danskheden stadig holder sig hedst, tog han i vestlig Retning over Agtrup til L $\mathrm{k}$. I Igtrup horte han en Del Track fra de to slesvigske Krige. I s t a d u n! Srdost for Lak fik han fat i et godt Sagn om Junkel ITy til Frisenhavn (S. 174). ${ }^{2}$ ) Megen Danskhed val der ikke at fincle i Fgnen her; heller ikke incle i sognet Enge (i Kanten af Frisland), hvorfra der meddeles en Del statistiske ()plysuinger om Sprogforholdene. Om Store Vi og sillerup er der ogsia $i$ denne Rejsebeskrivelse nogle Oplysninger, men der er dog me-

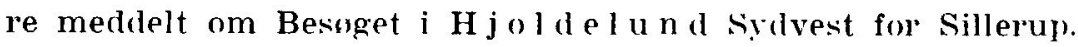
I det ensomt beliggente Hjoldelund har Danskheden ogsá holdt sig temmelig lange. Interessant er det at liese on Hoyers Samitale med Folkene i en Gârd i navnte By. De anede f. Eks. intet om Slaget pa Ly rsk o v He de 1043 (s. 181). Den folgende Dag besogte han en gammel Husar fra 186 iz. Iomme Mand havde

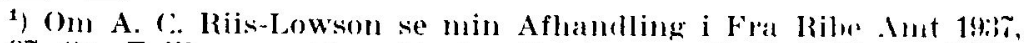

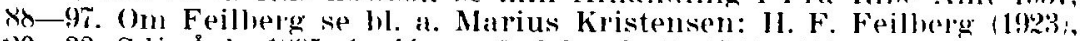
$20-33$. Sdj. Årb. 1695, 1-44, og Sylslesvig I 19333), $161 \mathrm{f}$.

2) Jfr. H. F. Feilherg: Fra Heden (1920), is ff. 
varet med i Retraten op genuem Jylland og kom bl. a. i Kvalter på Mors, hvor han sammen med andre Soldater blev indlogeret hos et I)egnepar. legnekonen var slem ved sin ganıle svigerfacler. Soldaterne trakterede den gamle med Brandevin. Nár Humbret pa den Made kom op, begrndte han at ș̣nge: "Tov lidt! sagde Jỵlen ved Frederiksstad.«') Husaren undrede sig over, at Deguen havde Traesko pa i Kirken. Det var han ikke vant til at se pa sin Hjemegn.

Syd for Hjoldelund ligger I'jolde, det danske sprog: aller sydligste (iranse. Hoyer gar imod den af P. K. Th o r sen opstillede Formodning, at sproget her maske skyldes en i fjeme Titter foretaget svensk Indvandring, da det har visse Afvigels'l fra Nabosognenes Sprog mod Nord.") "Former i sproget, der minter om syensk og (Xstransk, kall ligesaa goclt forklares af len afsicles Boliggenhed og det ringe Samkvem med Onıverlenen, livilket har bidraget til, at sproget her ikke har rulgt 'Trit med den almindelige Tdvikling, og at falles norliske Rester har kummet holde sigu (s. $18 x$ ).

Adskillige fortrinlige oplysuinger om det danske sprog 1 sollerup, Bondelum, Irnfjolde og Jorl sluttel Jorgon Hoyers omfangsrige Afhamdling. Fra Arnfjolde meddeles nogle gamle Marknavne, og fra (x) l's ed anfores Minder fra Kosaktiden. Trak fra gamlo Dages nojsomme Leveris far han ogsaa Lejlighed til at mediele, men det er her som overalt hos denne Forfatter Sprogforholdene og de nationals Tilstande, der interesserer starkest, og som der oplyses mest olin.

1) Jfr. Morsinghoer i gambe Tonge III (1936i), 93.

"1 P. K. Thorsen: Afhandlinger" og Breve I Cudg. af J. Byskov ou Marius Kristensen 19:27, 152 16:. Jfr. C. Mule: Minder fra den yderste danske Sproggranse i sonderjylland Sonderjydske Aarbinger

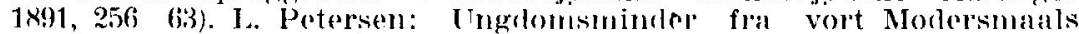

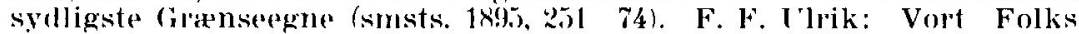

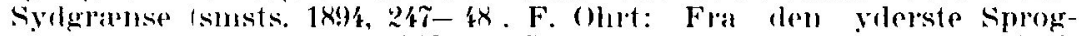
griense (J)anske Studier 1919, (61 70. Marius Kristensen: Sydslesvigsk

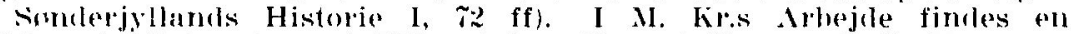
Mangrle Oplysninger i Tilknytning til vort Emme. J. B. Iloyer er navnt i det i Afsnittet: Studiet af det danske Sprogs Granser (Sonclerjyllands IIistorie I, X(i). I.itteraturhenvisninger smsts., 497500. 
Endelig skal omtales Høyers sidst beskrevne Rejse til vor Nations Grænseegne. Den gik i Oktober 1908 til ()en si i d (Bibliografien Nr. 5), hvor der ikke fandtes nuegent Danskhed. Der gives en snukt formet skildring af Øens Historie og Natur, og der anfores lidt om Silds Sagnoverlevering, ligesom den frisiske Byggestil i Kejtum, Uve Jens Lor I: e ns Fødeby, gøres til Genstand for nogle Bemarkninger.

Pá Hjemturen besøgtes Klangsbal og Gårien B on bal (herfra sagnet om Nis fra Bombul, der blev hollandsk . Iruiral). I E m me rsbo] var Kendskab til Dansk enduu mindre end i Klangsbøl. Tysk fik Indgang i Hjemmene under I'avirkning af Skoleungdommen. skildringen slutter med (ontale af et Besøg i B ov pá samme Rejse. Her holit manl ikke for stærkt på det danske sprog. Et godt $\mathrm{K}$ or $t$ over Egneu syd for Tonder ledsager Artiklerme om Rejsen blandt Nolilfriserne.

Den sidste Rejse, Hayer var ude ya til de truede sinngegne, fandt Sted i s o m me re n 1909 , men han mảtte afurrde den på Grund af Sygdom. Han mente selv, det var Forksielse; men det var vel nok Begrndelsen til den Sygdonı, der Jagde. ham i Graven. Han havile lagt 170 Mark til side til lortsiettelsen af denne Rejse; men da han markede, det gik mod Enren, traf han den Bestemmelse, at disse Penge skulde skankes til Sprogforeningen. ${ }^{1}$ )

Som vi har set, gjaldt tre af Hoyer's Rejser (Nr. 1, 3, ;i Marskegnene og to (Nr. 2, 4) den mellemslesvigske Hedeslette. På sime Rejser udspurgte han Praster og Lærere, Kromapul og Handelsfolk, Bønder og Arbejdere og alle andre Godtfolk, lian kunde komme på Talefod med. Han udviste en passende Tålmodighed og var utræattelig i $\sin$ Adfard. Ligesom $H . r$. C. I a se $n^{2}$ ) var han en ypperlig Fodganger. Han spadserede

1) Sprogforeningens Almanak 1912, 93 tJespel Marlsens Nekrolog. med Hoyers Billede).

${ }^{2}$ I)er et Sted i smukke Ord har omtalt Hoyer's Studierejser i Mellemslesvig. Jeg hal ikke kunnet finde, hvor Clausens Iditilolse er trykt. 
omkring i Gårde og Smahuse, besogte Embedsmandshjem og fattige Hedebonder, hyppig Genstand for Mistanke hos Folk, der enten stillede sig fjendtlig over for Danskheden eller var den ligegyldig. Gæstfrihed fandt han ikke altid, og mangen Gang mátte han vandre en hel Mil i Regn og Slud for at finde Nattely i en Landsbykro for så atter næste Dag at vandre samme Vej tilbage.

De Erfaringer; Jørgen Hoyer indhøstede på sine Undersggelsespejser i Mellemslesvig, kan opgures i få Ord: Plattysk rykker stadig, men langsomt mod Nord. Bevægelsen foregar sá langsomt, at bliver den ved at gå $\mathrm{i}$ samme Tempo som siden 1864, vil der hellgá 3 a 4 Menneskealdre, forend det danske Talesprog er uddøa i Mellemslesvig. Disse Høyers Resultater har i 1937 fra tysk Side fået deres Bekræftelse i Pa ul Selks Bog: Die sprachlichen Verhältnisse südlich der (irenze, hvori det med opbrdelse af meget statistisk Materiale pávises, at Sproggrænsen fremdeles løber syd for Rigsgrænsen. $\left.{ }^{1}\right)$

Høyers Rejseskildringer giver et frengslende Indtryk af Folks Sprog og Tænkemåde i de sydligste danske Egne. Det er et nyttigt Bidrag, han i sine fem Arbejder har leveret om de nationale Forhold i Overgangsegnene fra Dansk til Tysk. Et Bevis på den Væxdi, der er tillagt Høyers Afhandlinger, ses i clet Forhold, at hans Birlrag i smuderjydske Aarbøger 1905, 1 i2 (Bibliografien Nr. 2) om Rejsen i Hedelandet Vest for Flenshorg blev optrykt (og illustreret) i det ved (ienforeningen udgivne store Vark: "Sønderjylland" I (1919), 96-119 (redigeret af Svend Dahl og Axel Linvald). Det vilde have været af Vierdi, om Høyers fem Rejseskildringer var blevet samlede og udgivne i Bogform. Hans tidlige Død forhindrede desvarre en sarlan Tankes Realisation, ligesom den satte Bom for hans videre mellemslesvigske Studier. Kun 35 År gammel måtte den utrættelige Vandrer nedlægge sin stav. Han skulde lige

\footnotetext{
1, Jfr. Gransevagten (Marts 1934), hvor selks Bog el omtalt.
} 
til at begynde sin egentlige Livigerning, da sigdonmen afbrol hans Virksomhed. I Efteråret 1909 tog han, som vi véd, fat sonı Forstander for Skelund Hojskole. I)a var Helbredet allerede dărligt, og det gik stadigt tilbage. Iet kneb for ham at holde ud med Sommerskolen, men han blev pa sin Post til det sidste. Sa var hans Kraft brudt.') Han tyede til sit Hjem i vilslev l'ruentegård, hvor hans sygdom udvikledle sig saledes, at han efter lange og tunge Lidelser hensov den 3 . De c e m b e $\mathbf{r}^{\text {* }}$ $1910^{2}$ ) Han blev begravet Lordagen den 10. December $1910 \mathrm{pà}$ Vilslev Kirkegård.") Nogle faa skridt fra Kongeåens nordlige Bred redtes hans sidste Leje. Hans Dod var et dybt Savn for lians nximeste, og i den lille Vennekreds, lan havde vundet, lever Mindet om den stille, fordringslose og sandhedskarlige Mand rent og lysende selv nu sid lange efter, at hans Blik er slukt.

Hans varme, rige Hjerte drev ham til at rejse rundt $i$ sin Fritid nede blandt vore sydligste Landsmand. Hans Idrat $i$ Fedrelandets 'Tjeneste tilfredsstilledle hans dybeste Længsler. Jesper Ma d s e n karakteriserer ham som net ædelt, trofast og bravt Menneske, der sad inde med en bețdelig Kundskabstylde, men tillige med et forunderligt barnligt Sind, der let kunde blive misforstaaet af denne Verdens Vise.« -

Da narv. Forf. i 1926 og 1931 rejste rundt i Egnen: Flensforg - Store Vi - Lak Ladelund - Valsbol for at indsamle Folkeminder, var der tre Mænds Arbejder om Kultur-og Nationalitetsforholdene i Landet Sỵd for Skelbrkken, jeg idelig måtte tænke pă: H. F. Feilbergs, H. V. Clausens og J orge n B oy e Høy e r.s. På lange Fodture sammen med den meget lokalkendte $G u s t a v$ L indstrom erindrede jeg tit Hoyers prægtige Naturskildringer fra det flade Land med de

1) Skelund Højskole fik efter Hoyer V. Witt-Iansen til Forstander. I Sonmeren 1912 havde den 15 Elever. Den lille skole er forlængst nedlagt.

2) Hojskolebladet 1911, Sp. 73 it (Jesper Malsms Nekrolog, med Hayers Billede).

3) Højskolebladet 9/1? 1910 (I) (mlsannonce). 
store ('dsyn.') Det har (lerfor varet med saregne vemodige Fylelser, jeg nu pâny, i Tankerne og med J. B. Høyer som Fører, har foretaget en Rejse rundt til mange og dyrebare Steder i det tabte Land syd for Statsgrænsen. Denne Rejses Formâl har forst og fremmest haft til Opgave at fremdrage Mindet on en af de Maxnd, der med văgent Øje, rent sind og drevet af dyb Fædrelandskxrlighed tog sig den Opgave på at meddele sine Landsmand de bedst mulige Oplysuinger om Sprog og Nationalfolelse i de Egne af Danmark, hvor vort Folk må holde stand over for et overmagtigt Pres fra ell stor Nation, der vil tilegue sig Magten pă en Jord, hvortil Danskerne har gammel Odelsret. Jørgen Hoyer sá rigtigt, hans Fremstilling er præget af roligt Omdomme og nogterne Betragtninger. Han var klar over, at tysk sprog ikke let lod sig standse i sin Fremmarch mod Nord. Det foruncltes ham dog ikke at leve længe nok til "at se Nordens Grænsepæl atter rykket frem mod Sỵd «; thi sá vilde også han have oplevet sill storste nationale Glade.

Brabrand, 3. 2. 1938.

A ugus t F. schmidt.

1) Den skønneste og bedste Skiliring, der nu forefincles om nogenr sunderjydsk Egns Overfladeformer og Natur, er K n u d Ol riks Bidrag i "Sydslesvig" I (1933), 9-47. Her er det netop Mellemslesvigs Hedeegne, den udmærkerle Iagttager har haft så stor Lykke med sin Beskrivelse af. 